\title{
Am I Crazy or Spiritually Transforming? Beyond the Differentiation of Psychiatric and Spiritually Transformative Experiences
}

\author{
Janet Elizabeth Colli, PhD \\ Seattle, WA
}

\begin{abstract}
Spiritually transformative experiences (STEs) may sometimes present with the symptomatology of psychiatric disorders. Transformational crisis may even occur within the context of a psychiatric hospitalization. Such STEs are at odds with the medical model of Western psychiatry that emphasizes pathology. Yet a coherent approach yields no absolute differentiation between spiritual emergence and what health professionals diagnose as mental illness. A historical perspective begins with the presumed differentiation between authentic spiritual experience and psychiatric illness. A more functional approach to spiritual emergency takes into account the perspective of experiencers, their communication and meta-communication skills, and the integration process itself. One case from the popular literature and two cases from the author's psychotherapy practice are presented to demonstrate that the list of causative experiences for STEs can include what is diagnosable as a psychiatric condition, specifically, bipolar disorder.
\end{abstract}

KEY WORDS: spiritually transformative experiences (STEs); near-death experiences (NDEs); spiritual emergence; bipolar disorder; manic episode; psychosis

The case manager of a community psychiatric clinic recently called my psychotherapy office to ask, "How do I know if someone is experiencing

Janet Elizabeth Colli, PhD, is a licensed mental health counselor in Washington state. This paper is a condensed version of her presentation at the American Center for the Integration of Spiritually Transformative Experiences (ACISTE) 4th Annual Conference on Therapeutic Issues of Spiritually Transformative Experiences, October 20-22, 2016, Palm Springs, CA. Correspondence regarding this article should be sent to Dr. Colli at 4649 Sunnyside Ave. N., Ste. 341, Seattle, WA 98103, or e-mail: becolli@ mindspring.com. 
a spiritual emergency and needs a shaman, or if they're experiencing a symptom of a mental health disorder? I've taken a Transpersonal Psychology course at the California Institute of Integral Studies, and I still don't know the answer." Underlying that question is the suggestion that what mental health professionals diagnose as a mental or psychiatric disorder inherently belongs in a different category, that is, as something not spiritual. Of the many types of experiences listed as catalysts for spiritual transformation, psychiatric conditions such as bipolar disorder are not commonly included. Yet, in my clinical experience, spiritually transformative experiences (STEs) may sometimes present with the symptomatology of psychiatric disorders, and what is diagnosable as a mental disorder may initiate an STE. Transformational crisis may even occur within the context of a psychiatric hospitalization. In this article I present three cases-one from the popular literature and two from my psychotherapy practice-as evidence of a coherent approach that yields no absolute differentiation between an STE and what may be diagnosable as mental illness according to the current Diagnostic and Statistical Manual of Mental Disorders (DSM-V; American Psychiatric Association, 2013). A more functional approach to STEs takes into account the perspectives of experiencers, their communication and meta-communication skills, and their integration processes.

A historical perspective begins with thoughtful attempts to differentiate between authentic mystical experience and psychiatric illness and to acknowledge their overlap by the creation of new diagnostic categories, such as mystical states with psychotic features, or psychotic states with mystical features (Lukoff, 1985). However, Stanislav Grof, engaged in de-pathologizing difficult spiritual experiences, maintained that

the use of diagnostic labels obscures the issues and interferes with the healing potential of the process. In addition to its socially stigmatizing and psychologically damaging effects, it creates a false impression that the disorder is a precisely identified disease and serves as a justification for suppressive medication as a scientifically indicated approach (Grof \& Grof, 1990, pp. 256-257).

Indeed, one experiencer on a panel at the 2016 American Center for the Integration of Spiritually Transformative Experiences (ACISTE) conference tore up a copy of the DSM-V to dramatize his rejection of its stigmatizing and damaging effects. The DSM conforms to the medical model of mental distress - the disease model—by organizing so 
called mental disorders into discrete categories, just as medicine does with diseases. This panel participant rejected the use of this model altogether. Another more conventional route to de-pathologize difficult spiritual experience has been the inclusion of Religious or Spiritual Problem (V62.89) within the DSM as a V Code (Lukoff, Lu, \& Turner, 1992). V Codes are not necessarily primary diagnoses but are used to identify conditions other than a disease that may nevertheless warrant counseling and are used to report significant factors that may influence care. However, this course of cooperating with the medical community_-"If you can't beat them, join them"-may lose its appeal to mental health professionals because a psychotherapist may enter a DSM V Code on an insurance claim but will not be reimbursed because insurance companies do not cover treatment of $\mathrm{V}$ Code concerns regardless of how distressing the client's experience. Moreover, the use of a V Code depends upon differentiating spiritual experiences from mental disorders.

The spiritual emergency paradigm bypasses the DSM altogether, in an alternative to the medical model. Spiritual emergencies, "currently diagnosed as psychotic and indiscriminately treated by suppressive medication, are actually difficult stages of a radical personality transformation and of spiritual opening" (Grof, 2008). Christina and Stanislav Grof's introduction of the spiritual emergency paradigm proposed criteria for a complex differentiation between spiritual emergency and psychiatric disorders (Grof \& Grof, 1990, pp. 254-255). However, one symptom used as criteria, "voices" with a very unpleasant content, has since been found to remediate by the Hearing Voices approach (Romme \& Escher, 2012), that originated through the work of Professor of Psychiatry Marius Romme and a woman to whom he was providing treatment, Patsy Hage. The Hearing Voices Network USA (2011) is one of over 20 nationally-based networks around the world, incorporating a fundamental belief that many ways exist to understand the experience of hearing voices. It is an empowering alternative approach that does not start from the assumption that voice hearers have a chronic illness (Hearing Voices Network USA, 2011). This article demonstrates that it is possible to further expand the list of causative experiences for STEs to include yet another experience that would be diagnosable as a psychiatric disorder.

Personal trauma, illness, distress, or crisis can initiate STEs, as noted in the following quote from Jeffrey Kripal, who has held the J. Newton Rayzor Chair in Philosophy and Religious Thought at Rice University: "Extreme illness, car wrecks, and sexual abuse are par- 
ticularly effective inducers of the mystical" (Kripal, 2001, p. 29). It is widely acknowledged that some STEs can initially be frightening or distressing, as was my own STE that was catalyzed within the context of cancer (Colli, 2014a). The stress and tension that such traumas evoke often erupt in symptoms-challenging symptoms that contain the transformational potential of an STE.

Moreover, initiatory experiences practiced worldwide voluntarily invoke pain and stress specifically to induce transformation (Glucklich, 2001). Kripal seemed, though, to articulate extreme illness, car wrecks, and sexual abuse as initiatory experiences in a broader sense. People don't generally invite the experiences Kripal cited. Such an articulation serves to highlight the transformational potential of trauma and difficult symptoms.

Difficult symptoms may also signify a distressing aftereffect of an un-integrated STE that has already occurred. "Such experiences [STEs] may be catalysts for permanent and dramatic changes and positive transformation, or they may involve difficult challenges before the experience is completely integrated into the experiencer's life [emphasis added]" (Greyson, 2014, p. 124). Difficult challenges and symptoms may occur, amplify, process, and even resolve before the complete integration of an STE. Integration, after all, is a process that occurs over time. In this article I present three cases as evidence that those difficult symptoms may be diagnosable as a bipolar manic episode before the integration stage has reached completion.

Transcendent STEs can hardly happen only to mentally healthy people. Much less do STEs happen only to those who have achieved the criteria of self-actualization as a developmental step in a model similar to Maslow's (1964/1970) hierarchy of needs—with self-actualization at the pinnacle-as if STE's are the frosting on the cake of life. If frosting represents STEs, it would fundamentally alter that model to put the frosting inside a multi-layered cake, whose many layers represent causative experiences-such as the traumas that Kripal (2001) named-or symptoms that have not yet been processed or resolved as well as those that occur in the aftermath of an STE. Difficult symptoms may contain the transformational potential of an STE or may signify an un-integrated STE that has already occurred. Succinctly expressed by process-oriented psychologists, your biggest symptom may be your greatest dream trying to break through (Mindell, 1985). As humans have access to a plethora of experiences that initiate STEs, STEs can be seen to represent the human evolutionary potential, especially if, as Grof and Grof (1990) maintained, "the potential for a 
mystical experience is the natural birthright of all human beings" (p. 22).

Mental health professionals do not readily recognize the transformational potential of symptoms, largely because the dominant paradigm of the medical model of mental illness teaches that the more health professionals understand what a mental disorder entails, the more they will look "at it just as we would look at a physical health issue [cancer, diabetes or heart disease]. . . . after all, it is a brain disease [emphasis added]" (Holmes, 2016). The Director of the Alcohol, Drug and Mental Health Administration declared, "There is a boundary between the normal and the sick. There are discrete mental illnesses. . . . It is the task of scientific psychiatry . . . to investigate [their] causes, diagnoses and treatment [emphasis added]" (as cited in Whitaker, 2010, p. 46). An adherent to the medical model would answer the initial query of the psychiatric clinic case manager by drawing a definitive boundary between those with DSM diagnoses-'the sick'-and all other people-'the normals.' However, researchers investigating guild and financial interests of the psychiatric community have found that psychiatric diagnoses and treatments may have been influenced and even shaped by the pharmaceutical industry (Whitaker, 2010). STEs that have diagnosable symptoms-perhaps before the experience is fully processed and integrated-are at odds with the medical model of Western psychiatry that emphasizes pathology, for which psychiatric medication is the primary treatment. Beyond the medical model, "[difficult symptoms] traditionally seen as a sign of mental illness, may actually be the organism's radical effort to free itself from the effects of various traumas, simplify its functioning, and heal itself" (Grof \& Grof, 1990, p. 24).

STEs can likely be initiated within the context of experiences that meet the diagnostic criteria of many categories of the DSM, particularly during stages before the experience is completely processed and integrated. STEs have been initiated within contexts of complex post-traumatic stress disorder, developmental trauma disorder (Colli, 2014b), psychosis (Williams, 2012), bipolar disorder (Blackwell, 2011), and obsessive-compulsive disorder (Colli, 2017). In this article I focus on STEs initiated within the context of bipolar disorder. Far from being seen as indicative of purely pathological states, the diagnostic categories of the DSM can be seen as groupings of symptoms indicative of the potential for healing, particularly through STEs-which, like Grof and Grof (1990), I consider to be the natural birthright of all human beings. 


\section{Three Cases}

\section{First Case: No Missing Links with Mark}

According to Bengali saint Shree Maa, "the essence of spirituality is efficiency" (Swami Satyananda Saraswati, personal communication, August 2, 2016). One very efficient state of consciousness is the manic phase of bipolar disorder, at least as it strives towards connectivity and unitive consciousness, as my first case illustrates. My first case derives from the collective. The Eden Express is the evocative narrative account of Mark Vonnegut (1975), son of American writer Kurt Vonnegut, Jr. (1969) who is most famous for his dark, best-selling novel Slaughterhouse-Five. In 1969, Mark had newly graduated from Swarthmore when he was catapulted into a prolonged alteration of consciousness diagnosable according to the DSM as a manic phase of bipolar disorder, with psychotic features. He experienced profound altered and extreme states whereby he heard disembodied voices; possessed healing powers; and had hyper-acute sensory awareness and, at times, blissful and unitive consciousness, which he described as having "no missing links" (Vonnegut, 1975, p. 142). Efficiency is a constitutive attribute of unity consciousness, when connection is primary and the differentiation of subject-object consciousness is secondary. "Perfectly awful. Perfectly wonderful. Heaven. Hell. The intention changed, the next effect changed, but never the awesome symmetry, the dazzling perfection of it" (p. 141). Further quotations from Vonnegut's book illustrate his state of extreme connectivity whereby one unifying principle, such as the feminine principle, stood for all (material specimens):

... a feeling of already oneness.

When I looked at someone they were everything. They were beautiful, breathtakingly so. They were all things to me. The waitress was Eve, Helen of Troy, all women of all times, the eternal female principle, my mother, my sisters, every woman I had ever loved. . . . Faces glowed with incredible light. It was impossible to focus, to hate, to fix. They were so mobile, all moving, all changing. I loved them utterly. (Vonnegut, 1975, p. 117)

In addition to sensory phenomena, this overriding principle of connectivity applied to concepts, even religious, philosophical, and psychological systems of thought.

I've discovered some sort of shorthand . . . little microdots of thinking. I just go "dit" . . . and I've got the whole Bible. "Dit," all of Freud and 
then "dit" and the relationship of Freud and the Bible in one "dit.". . . I'm getting closer and closer to having it all in one "dit." I get it from time to time but can't seem to hold it very long. (Vonnegut, 1975, p. 119)

However, within a number of weeks, this connectivity progressed to the point where his inability to distinguish discrete physical objects, much less objects of thought, rendered him incapacitated.

Toward the end, a Donald Duck comic book, War and Peace, a Ravi Shankar album, the weather, my father, a hockey game on tv, all became interchangeable parts. . . . Like I said, the raw materials mattered less and less. (Vonnegut, 1975, p. 142)

Mark became increasingly disorganized; he could not speak save for indiscernible gibberish; he ceased eating and drinking; and he eventually experienced missing time, that is, a period of time where his normal, egoic consciousness was altered to the extent that he experienced memory loss for that period. During subsequent, multiple psychiatric hospitalizations Mark was diagnosed as schizophrenic. Yet he experienced many aspects of an STE, including transcendent, mystical, and ecstatic states. "It seems more than likely that there's a relationship between the two [schizophrenics and mystics], but what sets them apart is far more a matter of degree and circumstance rather than wisdom and virtue" (Vonnegut, 1975, p. 269). Given the degree of Mark's prolonged alteration of consciousness, all sense of efficiency in connectivity was lost as his functioning broke down.

Nonethless Mark underwent a sustained positive transformation or personality development over time. Mark's ordeal within the confines of a psychiatric ward initiated what was hardly a savior complex but rather was a genuine calling to a career in the medical profession. His next book (2011) was expressive of his growth as a pediatrician in control of his life. Though his later use of substances-meat, tobacco, alcohol and lithium (Vonnegut, 2011, p. 78)-hardly supported transcendence, those substances likely enabled him to "tamp down" or suppress the elevated states that his physiology naturally afforded access to. Mark's critically acclaimed first book achieved an altered state and transcendent tone that he could summon at least to some degree at will, whereas the stable balance he later found within his life spoke greatly to his personality development.

At the time of Marks' experience, however, it was not fully processed and integrated, especially given his misdiagnosis-by current psychiatric standards-of schizophrenia, and his maintenance medication with Thorazine. Mark had this to say about Thorazine: 
What I think it does is just fog up your mind so badly you don't notice the hallucinations or much else. ... I don't see [Thorazine or similar tranquilizers] as an attractive long-term solution but more as a way to buy time for the vitamin, dietary and other less coercive approaches [to work]. (Vonnegut, 1975, pp. 252, 274)

Not only would the different clinical diagnosis and treatment for bipolar likely have helped, but the medical approach allowed for no recognition of the spiritually transformative nature of his experience.

Further cause for lack of integration may be that segments of his experience remained unconscious and irretrievable; being statedependent memory, that is, having been encoded for memory during a particular state of consciousness, he had been unable to remember those segments without access to a similar state, in this case, psychosis.

Psychotic states involve a radically different state of consciousness than normal or altered states: A distinction can be made between the extreme states of psychosis, during which one lacks meta-communication skills, and altered states that allow meta-communication (Mindell, 1988). To meta-communicate is to communicate about the content of communication; it involves self-awareness, an aspect of egoic consciousness. Mark's states were sufficiently unrecognizable such that, at times, "Mark" was not present. "It keeps getting harder and harder to come back. I stop being Mark Vonnegut" (Vonnegut, 1975, p. 145). Although a good deal of his experience was spiritually transformative during the throes of a bipolar manic episode, it devolved into a manic episode with psychotic features. However, I maintain that cases of bipolar mania may sometimes qualify as STEs, if processed and integrated over time. My second and third cases exemplify such STEs.

As the following case will illustrate, one of my clients exemplified the differentiation between STE and psychosis. Unlike Mark's, this experience had no obvious spiritual basis, at least that I could determine in a limited context. I had a psychological consultation with a middle-aged man whom his sibling had identified as undergoing a spiritual emergency, the result of a series of catastrophic events. However, a face-to-face meeting found him prostrate, in a state of terror, and with little ability to meta-communicate, though he managed to describe his experience as like "being turned inside out." I progressed his image by responding, "or, like a snake losing its skin." Given his other symptoms, I diagnosed a brief psychotic episode due to prolonged severe trauma. A few months later, after being given neuroleptic medication by a conventional psychiatrist, he was again functional enough 
to contact me and to communicate that he was cobbling his life back together. An evolution, or transformation of the personality, indicative of an STE, was not as yet evident. Whether the experience can be further processed and integrated remains to be seen. Moreover, he evinced some memory loss_- "missing time"-for an episode in my office: Providing a cogent example of an extreme state, he did not remember shedding his clothes in the restroom and re-entering my office completely naked. The snake had, indeed, shed its skin.

\section{Second Case: Processing a Difficult Passage with Loreen}

Loreen sought me out for transpersonal psychotherapy, having already undergone two manic episodes, the first of which had resulted in a traumatic, psychiatric hospitalization. An avid documentarian, she was already making a record of her own story.

I was 20 years old working at a pizza shop in Seattle when I experienced my first manic episode. I was extremely overworked, and alone at home contemplating my life, obsessing about how disappointed I was about where I had ended up. I vowed that night to do whatever it took to have the life of a person I was proud of. It was this night of surrender that was the catalyst for an intense surge of energy and wisdom I was not prepared to handle.

With self-awareness born through that most difficult of challengesa prolonged bout with powerful transformational energies-Loreen identified an act of surrender as the trigger. I have found from other case work that a compelling act of surrender can initiate one into a radical shift of consciousness (Colli, 2017).

I basically went from depressed to what felt like pure peace in the duration it took me to write all that down. Life was exactly as I always hoped it would be. And then after a couple weeks when my sleep became non-existent, the psychosis really broke out. I couldn't get myself to eat or take care of myself. I knew something was happening to me but I took it more as a religious experience. My sister who is a nurse recognized my racing thoughts and rapid speech as bipolar. I related to this diagnosis, but it did not change how $\mathrm{i}$ felt knowing it was all "fake." It was real to me and I knew it was important.

Loreen intuited the significance of what was happening to her. Even a psychiatric diagnosis and subsequent hospitalization could not deter her from that conviction. Although her languaging only extended 
to a conventional "religious experience," that "something" might be more readily classified as spiritual. Thus began the lengthy process of learning to manage and modulate what Loreen deemed to be "important" energy.

Over the next year I did a lot of informal studying, studying my diagnosis and studying myself ... so that I could separate myself from my illness and understand my true self. I consciously moderated my thoughts and behaviors to match my new standards based on the lovecentered, non-dualistic philosophy I discovered during my extreme state.

That Loreen's manic episodes gave her "new standards" of nondualism for her thoughts and behavior illustrates a higher level of psychological functioning and spiritual awareness-those personality and behavior changes indicative of an STE. I cite her pre-event functioning as a depressed, troubled teen and young adult whose poor performance, struggles at school, and problems with emotional dysregulation, culminated in multiple arrests involving alcohol. After her manic episode and an integration phase of several years during which she consciously worked on emotional regulation, Loreen reentered college to work towards a profession in psychology to help others such as herself and to support change within Western psychiatry-a more rewarding life strategy.

This non-ordinary state of consciousness was spiritually enlightening and allowed me to look at myself from a new perspective that highlighted truth everywhere. ... I felt unconditional love for myself for the first time since I was a child, and I felt the same love for humanity. It was a transcendent transformative experience that taught me how to be the person I imagined myself to be, and what a beautiful person I already was.

Loreen's perspective on her process is paramount. Her story illustrates that, over time, the processing and integration of a difficult passage with bipolar mania may yet result in an STE.

\section{Third Case: Death and Rebirth with Adam, the Magellan of the Soul}

Having been diagnosed with bipolar disorder, Adam sought me out for transpersonal psychotherapy to process a single manic episode. After every attempt he made with his psychiatrist to explore his experience as meaningful, the doctor made an effort to increase his anti- 
psychotic medication. Yet Adam had been "astounded" to read The Cosmic Game: Explorations of the Frontiers of Human Consciousness (Grof, 1998) as it described so much of what he had experienced during his episode. Adam maintained from the start that bipolar disorder is not merely a disorder but is a complex biological function resulting in metamorphosis. "It's part of my nature-to be a risk taker. If I know something's possible, I run to the edge. Someone has to be the Magellan of the soul."

Adam's manic episode was initiated by the extraction of his wisdom teeth, for which the anesthetic ketamine was administered. He seemed to be "tripping lightly," and he related to the concerned anesthesiologist that he experienced himself flying through the corridor of a spaceship. In the following weeks, Adam remained altered and "started playing with consciousness itself." It was responsive to his physical movement, even his breath; he could raise it or lower it. "I found new ways to propel it. I consciously and purposefully egged it on-every step of the way." Adam stayed up all night, having "the time of my life." Sometimes he would rest, but sleep seemed superfluous.

Adam was seeing the world in a radically different way-two weeks before the visions commenced. He was aware that he was "out of sync" with everyone and that others were likely to think he had lost his mind. But he did not think so. Everything was happening on two levels at once: an ordinary level and a much higher level.

It wasn't like I was high and switched-on, while the other person was ordinary. Instead, it was like I was my high self, and as that version of me on that plane, I saw and heard [others'] high selves, too. Whatever happened would have a perfectly ordinary interpretation, so that if there had been an "ordinary" observer, they wouldn't have thought much of it. It was exactly like certain frequencies hiding in a signal. What you see or hear is all in the filtering.

Unfortunately, during that time, his "ordinary" relationships suffered due to his reliance on his "high self" and the incongruence between levels. Mathematicians and logicians consider this a type error, that is, when the rules and conditions of one level are applied to another inappropriate level. It was far easier to relate to non-human environments.

Nature. The mountain. The trees, the leaves, the undergrowth, the flowers - there was so much dazzling detail and energy. All of this beautiful natural intricacy flooded into this magical state of mind, and they magnified each other. I could see and feel this vibrant, thick energy palpably hanging around every plant, every leaf. Each patch of 
green was a new jolt of energy. I used my hands to trade this thick energy back and forth with the plants.

My feet found their own way up the trail. I didn't need to look down, only all around. I had no self-consciousness whatsoever ... I was only the forest, seen from a moving point of view. I was walking fast, but felt no burning or aching at all in my legs. I tried to feel my body and found that I couldn't, at all. . . . I kept checking, trying to feel weight in my limbs, but there was simply nothing. It was as if I was made of pure energy. The only thing I felt was freedom, total lightness, and a humming vibration being exchanged between me and the woods.

Another astonishing thing happened to mark his alteration of mind.

I remember looking at a sign, and realizing that I could not read the words. I could see the symbols on the sign, but they looked like nothing more than shapes carved in the wood. I went up close to the sign, and marveled at this.

The letters on the trail sign made no more sense than hieroglyphics or gibberish. As the process of exploring the frontiers of human consciousness became "self sustaining," his left-brain, language function shut down for a few days. He could neither read nor engage in computer programming, although he experienced enhanced right-hemispheric creativity. He could play the keyboard but could not negotiate the electronic controls for the act of recording. His loss of language use is reminiscent of a stage of Vonnegut's manic episode, although within the next week, Adam fully regained this ability and typed fluently on his computer keyboard. These alterations of consciousness support the viewpoint that a single manic episode can consist of multiple stages during its evolution.

The most intense period took place in Adam's apartment, without the disruptive interference of the relationship channel. Indeed, this introverted experience would be qualitatively different than a subsequent episode spent "around lots of people." "There was something special about the solitary experience that sets it apart." As we shall see, an interior focus will be necessary to complete two cycles of death/rebirth. Grof (2000) would concur:

When individuals experiencing this [manic] state can be convinced to turn inward, face the difficult emotions that remained unresolved, and complete the (re)birth process, the manic quality disappears from their mood and behavior. The experience [of the final stage of birth: Basic Perinatal Matrix IV] in its pure form is characterized by radiant joy, increased zest, deep relaxation, tranquility, and serenity. In 
this state of mind, people have a sense of inner peace and total satisfaction. Their joy and euphoria are not exaggerated to the point of grotesque caricature and their behavior does not have the driven and flamboyant quality characteristic of manic states (pp. 103-104).

In the meantime, for Adam there was nothing mundane about cleaning his apartment. It was one continuous uninterrupted motion, as if in a flow state, mixed with grace:

I was in constant motion, dancing around my apartment, and my cascading stream of verbal thoughts also gradually began to include more visual thought. ... I had the sense of being led through a vast spatial field of information along a path, as if I was viewing through a window in this world into another dimension, or as if I had been lifted into a higher dimension and was looking 'down' on many available paths through time.

I happened to look in the bathroom mirror, and I was struck as if by lightening by a wholly unprecedented feeling of love and acceptance. It wouldn't last, but for just that moment, I truly experienced the most complete love I had ever felt, and for once it did not seem to have as its object another person. I was enough. I was complete. I stood inside of the kind of moment during which choirs of angels shout, and then I turned and went into the hallway. I held my hands up and looked at them. Looked at myself. I seemed to be glowing. I seemed to be made of something different from flesh. Something new.

This was it. I had been promoted in some way, whether into a new body, or into some kind of new life. I had been cleansed. I was new, and this was a new beginning.

Subjectively for Adam time was "super-compressed." Hours were experienced as mere moments. Active at all hours, he slept only one hour a night. "[There was a] pivotal day that I really blasted off into another level of being, where, as amazing as it was for me, it began to be nearly impossible to communicate with others normally."

From this point onward, it doesn't make any sense for me to try to put things in chronological order. I was fully and powerfully immersed in an intense visionary experience, characterized by different sequences that were each like extremely lucid dreams. After each sequence, I would have a very distinct sensation in my head, like coming up or down on a drug or anesthetic, and this would mark the transition from vision, to 'regular reality.' In these 'down' times, I would sleep a little bit, or eat a few crackers, or use the bathroom.

He entered into a series of intense, guided visions in 3-D—all night long - of the path of all evolutionary life. Structured like movies, these sequences had beginnings and endings. "Throughout these few days, [the apartment] was like being in a different place. Brighter. More col- 
orful. There was so much meaning-always the feeling of some imminent appointment with destiny. Always the subtext that cosmic secrets were being revealed."

As a result of restricting his diet to only Wheat Thins, Adam was losing weight. Drinking dangerous quantities of water, he was acutely aware that he was "made of water." Everything seemed very fluid, and he imagined water raining down on him.

One time, when he stopped moving, his head went back and everything went white. "Some very large, conscious entity was inviting me into that white space." He lost his sense of self ("my ego burned off") and became completely absorbed by bright white light-it was the totality of everything: a form of love that is everything, all consciousness. Some aspect of it lasted for months thereafter.

Inside the white light, Adam was shown that the largest-scale structure of everything was very simple, like breathing. There was an up and down cycle; all time in the universe was that simple cycle. Breath was right at the center of existence. He also directly experienced the structure of the universe as the Sanskrit sound OM, a super-low vibration: a distillation of the base vibration of the universe.

According to Hinduism, Adam experienced Brahman, the ultimate impersonal reality underlying everything in the universe, from which everything comes and to which it returns. Of great significance to him is the oroboris-symbolizing existence as self-sustaining and renewing: infinite. Later that night, he came into contact with the void. He experienced being "way out in the vacuum of space. There was an emphasis on fertility in that space, bubbling and boiling with potential." Adam had seemingly acquired experiential knowledge of what physicists term the zero point field: "Zero, emptiness, void." "The light represented completion, while the froth in the void (zero point energy) represented the origin or foundation (a type of 'source' in itself)." Yet it was experienced as conscious: "As if something was probing my mind."

Adam experienced "communing with this massive thing that was happening to me. Interacting with this presence that was coming through in my writing, that was becoming more and more like a second person." Someone was telling him to type, which he did, without knowing what he was typing.

I was surprised by everything that showed up on the screen; first about time, physics—all stuff I'm interested in. Gradually, this [presence] started interjecting words, parentheticals. Like a guide, a fellow. I was overjoyed by this. Even if I were to write it off as ravings, I still like it. 
His guide was playful, witty, and liked plays on words. They had fun interacting. "It put on a show for me like I've never seen before." At one point, it took a turn. His guide introduced another personality. A polarity of light and dark was represented by the two personalities. He never saw either, but together they gave a rap performance, a "rap battle."

I said, "I can't sit and channel Satan." The other one reassured me it's not like that. He explained, "You can't have one without the other; we're a team, we work together." The two explained why humanity has to go through this, and why it's worth it, knowing how it's going to end. It left me on the floor, crying my eyes out from sheer joy. Tears of gratitude. The last verse was a climax, going faster and faster, to the most awe-inspiring, hope-filled thing.

Adam was typing furiously and fell prostrate on the floor, weeping tears of joy, whereupon he felt himself being physically picked up off the floor. "It was all around me. Like [unseen] hands picking me up." He ended up in an impossible position with regard to gravity. Though a tactile sensation, it had a corresponding physical result, unlike his ecstatic trail walk during which his body felt indefatigable but he got terrible blisters on his feet. Now, the subtle realm seemingly corresponded to the material, physical realm.

The guides' story of why human history "is the way it is" ends on a joke. According to them, "The solution to the problem of evil is humor." It doesn't end on death. It ends on a joke.

The very last line of the poem doesn't rhyme, and seems to trail off. I remember typing out with a lot of emotion, trepidation, dread over facing what I knew was coming. After all, this one speaking was the dark one. The one who represented death. And we all know death is coming. The voices were saying, "Don't worry. It's not that bad. We'll hold your hand through it. You are guaranteed to pass through that gate, whatever it consists of, for you."

Adam was being led close to death purposefully. It got really somber. "Just so you know, but you're going to have to die." They were gentle about it. There was lots of reassurance. But it was his understanding that they were going to take him right there. He lay down in the next room and experienced his physiological processes slowing down. He seemingly stopped breathing, and faded away. Then he came back. They had told him how to revive himself. They taught him something he could do to restart his heart. That cycle of the (re)birth process was complete. 
At the end of "vision week" in his apartment, Adam felt compelled to climb Tiger Mountain. After seven days of drinking excessive amounts of water and not eating, he came to a clear realization that he was going to die. Adam collapsed on Tiger Mountain. Staring up at the sky, he had a near-death experience (NDE) - a profound psychospiritual event. He saw a film streaming by: his entire life, frame by frame. He was then told that it was his choice to die, if he was really done with this life ("no harm, no foul"); or phone a friend for a "grounding connection." He called a friend, and she "talked me through it." He discovered a granola bar in his pocket and ate it. He got down the trail to the "heaven-like" parking lot. A crowd of people were in the lot-of all people, it was an expedition of nurses. Nurses sat with him and decided that he needed urgent care. They even gave him snacks.

In the ambulance on the way to the hospital, colors were coming at him ("like a loud bass"). Adam had "just entered heaven." He was "so happy to see the colors! The sunlight! It was so beautiful I could barely stand it." He felt like "the star of the whole entire world." It was completely delightful, "like a sitcom."

The experience of Brahman - being outside of time-was definitely a breakthrough. After that magical week, however, self-doubt set in. According to his guides, "You can live on the level you're at, or risk. But if you try to go past or breach a threshold, you'll also bring up some very negative things." During the next two months, Adam's longterm integration process commenced. As the sense of oneness faded gradually, it contrasted so much with his personality that he felt awful about himself, his mechanisms of shielding. He remembered past events, had "internal flashbacks," but interpreted events from a higher moral ground. Adam wrestled with questions like, "Am I a terrible person? Am I evil? Do I deserve forgiveness? Up to that point, I could sweep it under the rug. But it came into sharp focus." He actually confessed to people. This "descent into hell" took one year to learn how to manage it and not experience "the horror or the sting." A regular meditation practice has ultimately provided his greatest help in managing his self-referential, negative thoughts.

In conclusion, Adam has done much to process and integrate these altered and extreme states. Since that manic episode, he had one more episode that resulted in a hospitalization during which he, like Mark, was misdiagnosed with schizophrenia instead of bipolar mania, for which his elation and very high mood would have been key indicators, versus the "flattened" mood more typical of schizophrenics. 
Like Mark, Adam was also administered neuroleptic medication that proved ineffective.

The 2014 episode was very interesting too. Obvious differences: 98\% of it unfolded in public, often around lots of people. There was a huge amount of actual communication with many other people, some fruitful, and some of the sort that just made them think I was completely insane or dangerous. I spent a week "adventuring" on foot downtown, and I've hardly ever felt more alive. My identity became very fluid. But I've also found writings, and there was the same detailed exposition about the deep structure of consciousness.

Compared to his former "solitary experience" with its interior focus, Adam's next episode seemed less profound. Corroborating Grof (1998), it was perforce more difficult to "find a grounding connection" with "many other people," notably if they thought him insane or dangerous. Nonetheless, it is Adam's "adventuring" into the deep structure of consciousness-resulting in the evolution of the structure of his consciousness - that convinces me that his manic episodes initiated an STE. As a result of his long-term integration process, Adam has stabilized without psychiatric medication-though he takes dietary supplements; the depression that he had "flipped to" is steadily lifting; and his work has never been more rewarding.

I'm doing pretty well now. I try to monitor myself carefully, and I think I'm on the high end of normal. I'm making a lot of progress in most of my favorite subjects [physics and computer science], and getting a lot done.

Regarding the nature of this evolutionary process, transpersonal research has implicated the Basic Perinatal Matrices (BPMs) in bipolar disorder. From his earliest mappings with LSD psychotherapy, Grof (2000) has endeavored to extend the cartography of the psyche to include the birth process, the trauma of which, he has found from clinical observation, leaves deep unconscious imprints in the psyche. He referred to four dynamic stages of childbirth as BPMs, each with corresponding psychopathological syndromes (Grof, 2000, pp. 32-36). For the purpose of this article, it is enough to associate BPM I with experience prior to the uterine contractions of birth, undisturbed intrauterine life, and the 'oceanic' type of ecstasy of the 'good womb.' BPM II begins with birth contractions; yet, as the cervix remains closed, and there is 'no exit' from suffering, a sense of oppression, depression, and guilt feelings pervade. Grof maintained that the manic individual is energetically stuck reliving the final stages of the death- 
rebirth process: the transition from BPM III to IV. BPM III amounts to a hazardous yet heroic passage through the open cervix to BPM IV, with its enormous decompression and expansion of space: Birth. Or, as Adam maintained, metamorphosis.

Many of the otherwise puzzling features of manic episodes become easily understandable when seen in their relation to the dynamics of the perinatal matrices. Mania is psycho-genetically linked to the experiential transition from BPM III to BPM IV. It indicates that the individual is partially in touch with the fourth perinatal matrix, but [is] nevertheless still under the influence of the third.... The state the manic individual is craving and aiming for and has not yet consciously achieved [is birth]. (Grof, 2000, p. 102)

The birth process itself is life-threatening and brings a person close to death. The NDE is the paradigmatic STE. Grof's (2000) findings are reflected in the literal death and (re)birth Adam underwent. In the corroborative words of his guide, "You actually have to die. What you've been doing is bringing your body close to death. This is necessary for what you've asked to see." Moreover, there were two separate enactments of this death process: Slowing, stopping, then re-starting his heart in his apartment was likely a simulation: It "could've been virtual, or hallucinated"; but the part on Tiger Mountain was all too physically real. According to Adam, people jump from one level of reality to another at certain times. In the exact words of his guide, "You have already seen what is coming." Not for nothing was Adam reminded of Magellan, who achieved the circumnavigation of the globe for the first time in history. Engaged in the cartography of human consciousness, Adam has come to believe that humanity is on the verge of actually realizing the Next World. "God is not boring. Heaven is my state of mind."

Emma Bragdon (1988) has written about the "peak" of spiritual emergence as the experience "of the ultimate unity of all things, a mystical experience, a merging with the Divine which transcends verbal description. Among the positive effects of this process are increased creativity, feelings of peace and an expanded sense of compassion" (Bragdon, 1988, p.10). Adam experienced that peak-with aftereffects of increased creativity and a newfound sense of service, what he termed "a side affect" of unity consciousness. As for Adam's pre-event functioning, he had hardly laid claim to such elevated states before, at least not without the use of mind-altering substances. These were his fourth and fifth hospitalizations (2012 and 2014) and only diagnosed bipolar manic episodes, major depression having been pre- 
viously diagnosed. "In only a few hours [while manic], I had gone from feeling inspired to write a few blurbs about life, to spiraling upwards into realms of consciousness I had never visited 'unaided' before."

Adam is only now, four years later, more fully comprehending the STE to which his own physiology gave rise: "What I glimpsed seems to closely match 'Dharmakaya' in Buddhism." The experience of Dharmakaya-Truth Body or Reality Body-is timeless. Beyond conceptualization, the Dharmakaya is from whence all mental forms ('phenomena') arise and to which they return after their dissolution. In his book Wonders of the Natural Mind: The Essence of Dzogchen in the Native Bon Tradition of Tibet, Tenzin Wangyal Rinpoche wrote, "the omnipervasive Dharmakaya, the primordially empty natural state, is without dualism," and "the empty essence of mind is Dharmakaya" (Wangyal, 2000, pp. 159, 157). Adam's statement that "heaven is my state of mind" is, therefore, accurate, for the Dharmakaya is not heaven but the basis of all existence. Stabilizing access to such experience is a life project to which Adam feels called.

\section{Clinical Implications}

Bipolar mania can be fertile ground for the initiation of STEs, even if their integration may take considerable time-for that is what may be chiefly required by mood disorders: time. Time was essential to complete an egoic death process, as was most clearly illustrated in the case of Adam, nor did the development of emotional regulation, given such intense surges of energy, happen overnight. As an STE is associated with characteristic changes in knowledge and behavior, it takes time to integrate the knowledge garnered during the heightened states. New practices may be needed, just as Adam found that a regular meditation practice helped him to manage his negative thoughts in the aftermath of his STE. The difficulties inherent in spiritual emergencies, and the acute nature of STEs, require clinicians to attend to altered, and even extreme, states of consciousness. However, the integration stage may be where therapeutic support is also greatly needed. Indeed, my own therapeutic work with Loreen and Adam began during the integration phase of their processes.

Moreover, the impact of such cases on the clinician may require a reworking of what it means, as a mental health professional, to diagnose and treat someone while using the DSM. As a clinician, I endeavor never to lose sight of the transformational potential of symptoms, even the symptoms or criteria by which psychiatric or mental 
illness are diagnosed-sometimes even within the context of a psychiatric hospitalization. Acknowledging the transformational potential of difficult symptoms will stand clinicians in good stead to facilitate the active and integration stages of both spiritual emergencies and STEs.

The cases of Mark, Loreen, and Adam illustrate that STEs, and what can readily be diagnosed as a psychiatric disorder, are not necessarily mutually exclusive experiences. In truth, I have never been persuaded by the medical model of mental illness. But rather than shred my copy of the DSM and forgo its diagnostic categories, or strive to overthrow the medical model by eschewing it, I envision working within the mental health community to transform it-as an insider, so to speak. What is required from me as the clinician is not to let the diagnostic category of bipolar disorder deter me from seeing it as a potential evolution toward what may be termed "higher consciousness."

\section{Conclusion}

This article began with a question about the differentiation between spiritual emergency and mental health disorders. Cases such as Mark's, Adam's, and Loreen's, that involved psychiatric hospitalizations as a result of a diagnosable psychiatric disorder, nonetheless may qualify as STEs. Rather than a strict differentiation or boundary between the psychiatric and the spiritual, these cases required a more functional approach that took into account the perspective of experiencers and their integration processes over time. The perils of bipolar mania may yet result in the successful negotiation of the final stage of the death-rebirth process. Adam cycled through a death process more than once, one passage of which included an NDE; and he underwent an extensive integration process that lasted over several years. Loreen's process, though not as extensive, nonetheless also resulted in the evolution, or transformation of her personality, indicative of an STE. At least one psychiatric disorder, bipolar disorder that includes a manic episode, may be regarded as an engine of the evolution of consciousness.

Even though it arguably saved Adam's life, a psychiatric hospitalization within the medical model of Western psychiatry that emphasizes pathology was ultimately not the only perspective or strategy with which to support or even interpret such a process. This experiencer maintained that bipolar disorder is not merely a disorder but is a complex biological function resulting in metamorphosis. Such a claim merits further consideration. If it is a biological function, it 
may follow that support for the physiology of the person would make a discernable positive difference, for example, an approach that entails dietary change and specific supplements. Further research is also indicated regarding the psychotherapeutic stance and interventions that most help the person undergoing the metamorphosis-to harness these particularly unruly energies of transformation.

\section{References}

American Psychiatric Association. (2013). Diagnostic and statistical manual of mental disorders (5th ed.). Washington, DC: Author.

Blackwell, S. (2011). Am I bipolar or waking up? Amazon.com: CreateSpace.

Bragdon, E. (1988). A sourcebook for helping people in spiritual emergency. Los Altos, CA: Lightening Up Press.

Colli, J. (2014a). From trauma to transcendence: Clinical perspectives on an evolutionary process. Journal of Near-Death Studies, 33(3), 99-110. doi:10.17514/ JNDS-2014-33-3-p99-110.

Colli, J. (2014b). The dark face of heaven: True stories of transcendence through trauma. Amazon.com: CreateSpace.

Colli, J. (2017). The dark face of heaven: Transformational crisis. Unpublished manuscript.

Glucklich, A. (2001). Sacred pain: Hurting the body for the sake of the soul. Oxford, England: Oxford University Press.

Greyson, B. (2014). Differentiating spiritual and psychotic experiences: Sometimes a cigar is just a cigar. Journal of Near-Death Studies, 32(3), 123-136. doi:10.17514/JNDS-2014-32-3-p123-136.

Grof, S. (1998). The cosmic game: Explorations of the frontiers of human consciousness. Albany, NY: State University of New York Press.

Grof, S. (2000). Psychology of the future: Lessons from modern consciousness research. Albany, NY: State University of New York Press.

Grof, S. (2008). Spiritual emergencies: Understanding and treatment of psychospiritual crises. Retrieved from http://realitysandwich.com/1800/spiritual_ emergencies/.

Grof, C., \& Grof, S. (1990). The stormy search for the self. New York, NY: G. P. Putnam's Sons.

Hearing Voices Network USA. (2011). Hearing Voices Network USA: Hearing voices, visions and other unusual or extreme experiences. Retrieved from http:// www.hearingvoicesusa.org/.

Holmes, L. (2016). We need to change the way we talk about mental health. Retrieved from http://www.huffingtonpost.com/entry/mental-health-terminology _us_57c83627e4b078581f114f11.

Kripal, J. (2001). Roads of excess \& palaces of wisdom: Eroticism \& reflexivity in the study of mysticism. Chicago, IL: University of Chicago Press.

Lukoff, D. (1985). Diagnosis of mystical experiences with psychotic features. Journal of Transpersonal Psychology, 17(2), 155-181.

Lukoff, D., Lu, F., \& Turner, R. (1992). Toward a more culturally sensitive 
DSM-IV. Psychoreligious and psychospiritual problems. Journal of Nervous and Mental Disease, 180(11), 673-682.

Maslow, A. H. (1970). Religions, values, and peak experiences. New York, NY: Penguin. (Original work published 1964)

Mindell, A. (1985). Working with the dreaming body. Boston, MA: Routledge \& Kegan Paul.

Mindell, A. (1988). City shadows: Psychological interventions in psychiatry. New York, NY: Routledge.

Romme, M., \& Escher, S. (Eds.). (2012). Psychosis as a personal crisis: An experience-based approach. New York, NY: Routledge.

Vonnegut, K. (1969). Slaughterhouse-five. New York, NY: Delacorte.

Vonnegut, M. (1975). The Eden express. New York, NY: Bantam Books.

Vonnegut, M. (2011). Just like someone without mental illness only more so: A memoir by Mark Vonnegut M.D. New York, NY: Bantam.

Wangyal, T. (2000). Wonders of the natural mind: The essence of Dzogchen in the native Bon tradition of Tibet. Ithaca, NY: Snow Lion.

Whitaker, R. (2010). Anatomy of an epidemic: Magic bullets, psychiatric drugs, and the astonishing rise of mental illness in America. New York, NY: Broadway Books.

Williams, P. (2012). Rethinking madness: Towards a paradigm shift in our understanding and treatment of psychosis. San Rafael, CA: Sky's Edge. 